\title{
COMPADRAZGO Y RECIPROCIDAD EN LOS ANDES COLOMBIANOS: EL CASO DE GUALMATÁN (NARIÑO). COLOMBIA
}

\author{
COMPADRAZGO AND RECIPROCIDAD IN THE COLOMBIAN ANDES: \\ THE GUALMATÁN (NARIÑO) CASE. COLOMBIA
}

\author{
Mauricio Chamorro Rosero*
}

\begin{abstract}
El artículo presenta a la institución del compadrazgo como una estrategia que permitió sobrellevar el intercambio contractual del mercado a partir de establecer y fortalecer relaciones de producción basadas en la reciprocidad, las que se sustentan en una obligación moral. Mediante el trabajo etnográfico realizado en Gualmatán se describen los tipos de compadrazgos, las maneras de constituirlo y su relación con la reciprocidad andina. Sin embargo, como consecuencia de los procesos modernizantes de cambio agrario, en la actualidad la institución del compadrazgo comienza a resquebrajarse. Por esa razón, se analiza finalmente la transformación y adaptación del compadrazgo a los nuevos contextos sociales.
\end{abstract}

Palabras claves: Compadrazgo, reciprocidad, Andes colombianos, Gualmatán.

The article presents the institution of compadrazgo as a coping strategy that allowed the contractual exchange market from establishing and strengthening relations of production based on reciprocity, which are based on a moral obligation. Through ethnographic work in Gualmatán compadrazgos types, ways of their establishment and their relationship with the Andean reciprocity described. However, as a result of the modernizing process of agrarian change, today the institution of compadrazgo begins to crumble. For that reason, finally it analyzes the transformation and adaptation of compadrazgo to new social contexts.

Key words: Compadrazgo, reciprocidad, Colombian Andes, Gualmatán.

\section{Introducción}

A partir de la primera mitad del siglo XX en las zonas rurales de los Andes colombianos, el proyecto modernizante se concentró en transformar las viejas estructuras de la economía campesina, que hacían a la producción agraria obsoleta e incompetente en el mercado capitalista, con el fin de generar procesos de cambio agrario. Sin embargo, las estructuras de la producción agraria antes de los procesos de cambio se soportaban sobre la familia campesina, por lo que fue una de las primeras instituciones en transformarse.

La familia campesina es el reducto más íntimo de las estructuras sociales y económicas campesinas (Wolf 1978). Por este motivo, a partir de las políticas de cambio agrario, la familia campesina ha sido reconfigurada y, en algunos casos, su importancia como principal unidad de producción agraria ha sido remplazada por el trabajo asalariado; resultando el cambio agrario -por una parte- como un proceso de proletarización del sector rural.

Concretamente, el cambio agrario ha incidido en la reconfiguración de la familia campesina y en la economía campesina. Así las cosas, el compadrazgo, que otrora era útil a la reproducción económica de la unidad de producción familiar (Mintz y Wolf 1994) y era un elemento importante en las prácticas de reciprocidad (Alberti y Mayer 1974), ha ido desapareciendo como relación social de producción. En su remplazo, toda una lógica societaria -en oposición a una lógica comunitaria- ha sido incorporada a la producción agraria de la familia campesina.

Teniendo en cuenta que la institución del compadrazgo "es una de las características más universales de la estructura social de la sociedad indígena y mestiza rural en Iberoamérica" (Nutini y Bell 1989); la familia campesina de los Andes colombianos -concretamente la del municipio de Gualmatán- se caracteriza por la presencia del parentesco ritual (compadrazgo). Lo anterior implica que el compadrazgo se encuentra incorporado al sistema de parentesco y, por consecuencia, a la familia campesina extendida.

En este sentido, la intención principal del presente artículo es analizar la institución del compadrazgo presente en los Andes de Colombia, específicamente en el municipio de Gualmatán, como una estrategia que permitió sobrellevar el intercambio contractual del mercado a partir de establecer y fortalecer relaciones de producción

* Universidad Cooperativa de Colombia. Medellín, Colombia. Correo electrónico: alvarom.chamorro@ campusucc.edu.co 
basadas en la reciprocidad, las que son sustentadas en una obligación moral. Este trabajo está basado en la recolección de datos etnográficos entre los años 2014 y 2015. Se realizaron entrevistas a diferentes habitantes del municipio, observación participante (conversaciones informales) y el análisis de diferentes materiales bibliográficos.

Para desarrollar la temática expuesta, este artículo se divide en tres partes. En la primera sección se introducen algunos elementos conceptuales que permiten comprender la institución del compadrazgo y la reciprocidad. En la segunda sección se presenta el trabajo etnográfico realizado en Gualmatán, determinando los tipos de compadrazgos, las maneras de constituirlo y su relación con la reciprocidad andina. Finalmente, en la tercera sección se analiza la incidencia del cambio agrario en la institución del compadrazgo. Como veremos, el proyecto modernizante y la migración rural-urbana disolvieron varias prácticas de reciprocidad que sustentaban el compadrazgo, no obstante, la institución del compadrazgo no ha desaparecido por completo.

\section{Acotaciones Previas acerca de la Institución del Compadrazgo}

El sistema de parentesco ${ }^{1}$ es uno de los universales de la sociedad humana, se encuentra presente en la totalidad de las sociedades, desde las más arcaicas hasta la moderna sociedad industrial. Sin embargo, el parentesco se altera en las diferentes sociedades, esto debido a ciertas particularidades que generan modificaciones en la estructura sin perder de vista el importante papel que desempeña, tanto en la regulación de la conducta como en la formación de grupos.

Desde diversos trabajos antropológicos (Radcliffe-Brown y Forde 1982; Lévi-Strauss 1998; Harris 1990), el sistema de parentesco se ha fundamentado en dos ideas o principios mentales que intervienen en su organización y funcionamiento. La primera es la idea de afinidad o de relaciones por medio del matrimonio; la segunda, la idea de filiación o de las relaciones de descendencia biológicas $^{2}$. De esta forma, las personas relacionadas entre sí mediante la filiación o de una combinación de afinidad y filiación se consideran parientes y estructuran la familia (Harris 1990).

No obstante, la noción de familia en la vida campesina pocas veces se limita a los principios biológicos (filiación) y de alianza (afinidad) que la subyace, ya que en su contenido intervienen algunas complicaciones económicas y domésticas (Chayanov 1974). Lo anterior indica que existen sistemas de parentesco que se fundamentan en un tercer principio mental, en donde las relaciones no únicamente se originan en el hecho de la descendencia o la alianza. Estas relaciones han sido conceptualizadas de seudoparentesco y, según el antropólogo Pitt-Rivers, corresponden a tres grandes tipos: uso figurado, uso consuetudinario y parentesco ritual.

Podemos distinguir tres tipos de seudoparentesco: (1) Tenemos ante todo, el uso en sentido figurado de los términos de parentesco, que puede no ser más que una convención o, por el contrario, denotar una posición dentro de la sociedad o dentro de un contexto específico. (2) Existen también costumbres en virtud de las cuales se confiere a una persona la condición de pariente por atribución y no por nacimiento; es lo que suele llamarse parentesco "ficticio" o "artificial". (3) Hay también instituciones que, en ciertos aspectos, se parecen al parentesco y que reciben su nombre por analogía con este, pero que, no obstante, tienen una naturaleza distinta y suponen una condición diferente. Estas instituciones se consideran a veces, acertadamente, como formas ritualizadas de amistad (Pitt-Rivers 1975:597).

De estos tres tipos de seudopartentesco, encontramos uno que constituye vínculos más análogos a los lazos de parentesco tradicionales ${ }^{3}$, en donde los participantes reconocen un vínculo que es asimilado al parentesco y que puede o no confundirse con él, este es el caso del parentesco ritual de compadrazgo.

Para los estudios concernientes a las familias campesinas que se concentran en América Latina es indispensable tener presente la interiorización parental del compadrazgo a los grupos sociales. Según Sidney Mintz y Eric Wolf, el compadrazgo "designa el complejo particular de relaciones establecidas principalmente entre individuos, aunque no siempre, a través de la participación en el ritual del bautismo católico" (1994:371). Una definición más amplia, y que no limita el compadrazgo al bautismo católico, puede encontrarse en el trabajo que Nutini y Bell realizaron en Tlaxcala, México: 
El compadrazgo es una relación que se establece entre dos individuos, parejas o un número establecido de gente afín (parientes y no parientes) a través del vínculo de una persona, imagen, objeto u ocasión. Sin duda, el vínculo es la causa necesaria de la relación de compadrazgo, porque sin la mediación de una persona, imagen, objeto u ocasión (la entidad mediadora) es imposible establecer tal relación (Nutini y Bell 1989:62).

Por su parte, el profesor Jesús Contreras aborda el compadrazgo como una institución de implicaciones religioso-morales, económicas y sociopolíticas; destacando que el compadrazgo constituye una estrategia, más o menos consciente, de alianzas en vistas a la consecución de objetivos económicos y políticos (Contreras 1979:5). Posteriormente, dichas alianzas ordenan un sistema de clientelaje institucionalizado que ofrece seguridad a cambio de ventajas para el compadre, cuya racionalidad se deriva del mercado general (Golte y De La Cadena 1986). En este sentido es posible distinguir, según la dirección de la alianza, al menos dos arquetipos de relaciones de compadrazgo: el compadrazgo horizontal y el compadrazgo vertical (Foster 1953; Mintz y Wolf 1994; Contreras 1979; Gascón 2005).

El compadrazgo horizontal se presenta cuando la alianza se da entre miembros de un mismo estatus, es decir, entre personas que aparentemente se encuentran en una igualdad económica, política o social. Para el caso de los Andes, el compadrazgo horizontal se presenta cuando la alianza se da entre campesinos-agricultores/ganaderos, o entre campesinos-jornaleros, o entre no campesinos (comerciantes, empleados u otros) $)^{4}$.

Por su parte, el compadrazgo vertical se establece entre personas de diferentes estatus, personas consideradas por ellas mismas o por personas externas en aparente grado de desigualdad frente a la otra, ya sea de tipo económico, político o social. De esta forma, el compadrazgo vertical andino se presenta entre campesino-jornalero y campesino-agricultor, o entre cualquiera de estos y alguien considerado no campesino.

Como asegura Jesús Contreras, "el código normativo del compadrazgo es el mismo tanto para el compadrazgo horizontal como para el vertical" (1979:8). Sin embargo, el compadrazgo horizontal genera obligaciones morales encaminadas más a la ayuda mutua en la producción agrícola, que a la entrega de obsequios, regalos o favores de índole político. El compromiso de la relación horizontal se encuentra dirigido a la búsqueda de la cohesión social. Al contrario, cuando el compadrazgo es vertical las obligaciones morales producto de esta alianza permiten consolidar o fortalecer uniones políticas, además de crear lazos clientelistas. El compromiso moral de la relación vertical busca conquistar unos objetivos políticos o económicos determinados.

Es importante mencionar que la reproducción de la familia campesina se ve entretejida por la economía moral (Thompson 1991; Scott 1987), donde los lazos parentales y las relaciones recíprocas se manifiestan. Las obligaciones morales con las que principia el compadrazgo se constituyen como un elemento importante en la práctica de la reciprocidad. Esto significa que la institución del compadrazgo genera un sistema que contiene ideas compartidas acerca de los que se considera obligatorio y que son conservadas y reproducidas por todos los miembros de la comunidad, lo que Emilia Ferraro (2004) denomina como la "moralidad de la reciprocidad".

\section{Reciprocidad y Compadrazgo}

Según Marcel Mauss, en su texto clásico Ensayo sobre el don, en algunas sociedades denominadas arcaicas existen algunos mecanismos espirituales que obligan a devolver el presente recibido (2009:79). Este tipo de prestaciones se despliega en el ámbito jurídico y económico, y "comprende no solo la obligación de devolver los regalos que se reciben, sino que supone otras dos tan importantes como ella: la obligación de hacer, por un lado, y la de devolver, por otro" (Mauss 2009:91).

El principio de dar hoy y recibir mañana se sustenta en un modelo simétrico de organización que Karl Polanyi -atendiendo a los trabajos etnográficos de Malinowski y Thurnwald ${ }^{5}$ - lo ha llamado de reciprocidad. Sin embargo, a diferencia de Mauss, para Polanyi "la reciprocidad y la redistribución son principios de comportamiento económico no solamente aplicables a las pequeñas comunidades primitivas sino también a los grandes y ricos Imperios" (1989:426).

De esta manera, el principio de reciprocidad revela las formas que han adoptado las relaciones económicas en los distintos periodos históricos. 
Este sistema de relaciones basadas en la reciprocidad tiene un doble propósito. Primero, permitió optimizar la consecución de mano de obra para el desarrollo de actividades cotidianas. Segundo, el participar en estas actividades otorgaba a las personas la posibilidad de ampliar y fortalecer los lazos con sus compañeros y vecinos. Este entramado de relaciones consuetudinario organiza un modelo en el que cada persona es consciente que tiene el derecho de buscar la ayuda de los demás, si esta a su vez prestó su ayuda en el pasado, la reciprocidad se convierte en una forma racional de intercambio velado por formas de comportamiento ceremonial (Alberti y Mayer 1974). El modelo ideal de reciprocidad parte de tres principios básicos para su funcionamiento: la reciprocidad, la redistribución y el control vertical de la ecología:

\begin{abstract}
Así, mientras que los miembros de las comunidades rurales (o ayllu $u^{6}$ ) unidos por vínculos de parentesco, entran en relaciones recíprocas igualitarias entre sí, sobre todo en las relaciones de producción, el Estado Inca se vincula con ellos por medio de la reciprocidad asimétrica y la redistribución. El Inca, como centro de convergencia y de emergencia de toda actividad en el mundo andino, recibe de sus súbditas prestaciones de trabajo en la tierra directamente controladas por él: les redistribuye asegurando la paz del imperio, redistribuyendo productos escasos de necesidad, cumpliendo funciones religiosas, etc. La base estructural que sustenta la reciprocidad en el interior del ayllu está dada por la posición común de la tierra, explotada comunitariamente (Alberti y Mayer 1974:13).
\end{abstract}

No obstante, el modelo ideal de reciprocidad, orientado y estimulado por los que Emilia Ferraro (2004) denomina "andeanismo", idealizó las relaciones de reciprocidad desde una perspectiva simétrica. De esta forma, el andeanismo proporcionó "la imagen de un 'mundo andino' muchas veces definido como un todo atemporal, estático, homogéneo e igualitario" (Ferraro 2004:36), lo que se opone al sistema de economía mercantil impuesto por varios siglos de expansión colonial en los Andes.

Para William Mitchell (1994), el énfasis que los estudios hacen acerca de la reciprocidad simétrica, ha ocultado el carácter asimétrico de la reciprocidad andina, en el que unos pocos se benefician de muchos. En este sentido, Mitchell asegura que la reciprocidad puede ser simétrica o asimétrica. La primera se respalda en la visión idealizada del mundo andino, y la segunda se relaciona con estrategias de dominación que permiten la obtención de determinados servicios a favor de las clases dominantes. "La gente de la ciudad y los campesinos ricos mantienen vínculos recíprocos generalizados con los pobres no solo para obtener mano de obra sino para obtener productos agrícolas y otros productos" (Mitchell 1994:195). Igualmente, la reciprocidad puede sustentarse en una relación contractual y balanceada, que podría denominarse reciprocidad particular; o en una relación generalizada donde la gente aparentemente se ayuda sin ninguna expectativa específica de devolución, lo que podría denominarse reciprocidad generalizada (Mitchell 2004).

En todo caso, los sistemas de parentesco cobran vital importancia en el modelo de reciprocidad. La necesidad de convocar fuerza de trabajo ofrecía la posibilidad de reunir a personas cercanas para alcanzar un objetivo. Sin embargo, cuando se requería, era imprescindible la ayuda de la persona que inicialmente se había beneficiado con la fuerza de trabajo de sus allegados. Las prestaciones se cuentan para ser devueltas en la misma forma y cantidad $^{7}$, "en el sistema de reciprocidad lo que está en juego no son las cosas, son las personas" (Salazar 2010:57).

La reafirmación de la reciprocidad mediante el fortalecimiento y creación de los lazos familiares y rituales fundamenta un sistema normativo implícito de participación, derechos y obligaciones que acrecienta la base de la comunidad. De esta forma, la institución del compadrazgo, como estrategia de reproducción y relación económica particular, se encuentra entretejida por el principio de reciprocidad, el que se ha constituido como determinante y organizador de las prácticas económicas y sociales a las que ha dado lugar dicha institución.

Acrecentar las redes familiares y de compadrazgo aumenta la posibilidad de tener un mayor reconocimiento dentro de la comunidad, siempre y cuando estas se formen en torno al reconocimiento de los otros y a la forma de cómo las personas han sido responsables con su comunidad. El individuo tiene la posibilidad de servir a su comunidad cuando su presencia sea requerida y sí ha correspondido de buena manera a ese llamado, poniendo a disposición 
de la comunidad su red de relaciones, acrecienta su derecho sobre la misma cuando él la requiera.

Las relaciones de familiaridad reflejan una gran red de contribuciones que permiten la supervivencia del modelo de reciprocidad. De manera directa se depende de familiares cercanos y lejanos, además del compadrazgo, de los cuales se espera cierta responsabilidad y la que genera ciertas obligaciones por parte de los participantes. El compadrazgo es una de las características más destacables dentro de la reciprocidad. La persona que participa por medio de esta relación en una familia es considerada parte de la misma y se espera que esta relación sea de larga duración, bajo las premisas de corresponsabilidad y de obligaciones que ella implica. La responsabilidad de participar en una relación espiritual aumenta con el tiempo.

En este orden de ideas, la familia campesina ampliada, que incluye parientes rituales como los compadres, permite que la fuerza de trabajo se incremente y que la relación entre unidad de producción y unidad de consumo se equilibre; lo que además facilita un incremento en el volumen de su actividad económica. Lo anterior se explica porque "una de las consecuencias más directas de la extensión del grupo exogámico por medio de lazos de parentesco ritual fue presionar sobre los requisitos existentes para suministrar una fuerza de trabajo estable" (Mintz y Wolf 1994:382).

De esta manera, se puede afirmar que el compadrazgo permite la trasferencia de recursos que se sustentan "en relaciones personales construidas por obligaciones morales y que son fundamentales para llevar a cabo la producción dentro del sistema capitalista, y en general su reproducción social" (Narotzky 2010:151). La institución del compadrazgo es una estrategia de reproducción que permite el sostenimiento de la estructura de las relaciones sociales, en las cuales se generan las actividades de producciones económicas y simbólicas.

En conclusión, siguiendo los aportes de Susana Narotzky, el compadrazgo se caracteriza por tres aspectos: separarse del intercambio contractual del mercado a partir de establecer y fortalecer relaciones de producción basadas en la reciprocidad, sustentarse en una obligación moral (que consolida derechos) y producir cohesión social (2010:152). Adicionalmente, para Jorge Gascón (2005), el compadrazgo ha permitido crear y mantener uniones políticas y consolidar lazos clientelistas.

\section{El Compadrazgo en Gualmatán}

Gualmatán es un municipio que se encuentra ubicado en el Sur de la región andina de Colombia, en el departamento de Nariño. Su vocación económica es agrícola y cerca del $80 \%$ de la producción agrícola del municipio se encuentra en cabeza de pequeños agricultores. Adicionalmente, por su cercanía con la capital del departamento (San Juan de Pasto) y sus características productivas agrarias, Gualmatán fue uno de los principales municipios andinos que se incorporó a los planes de desarrollo del departamento. Para la década de 1950, en Gualmatán hacían presencia instituciones gubernamentales que buscaban el cambio agrario.

Sin embargo, pese a la transformación del municipio a partir de los procesos de cambio agrario presentes en las últimas seis décadas -procesos materializados con la inclusión de la Revolución Verde, la reforma agraria institucional y, actualmente, con paquetes de créditos y microcréditos productivos-, en Gualmatán aún subsisten algunas relaciones de reciprocidad y redistribución que, como asegura Andrés Guerrero para el caso de los Andes ecuatorianos, funcionan como mecanismos de reproducción social de unidades domésticas de subsistencia (Guerrero 1991:154).

Según la información del Anuario Estadístico de Nariño 1993-1994, el año de fundación del municipio de Gualmatán es 1830 y sus fundadores fueron Francisco Chalapud, Acensio Tepud y José Cuaspud. Sin embargo, según la tradición oral el año de su fundación es de 1734, el estudio se remonta unos 260 años atrás. El primero de julio de 1881 Gualmatán fue elevado a municipio mediante acto administrativo ordenanza II, expedida por la municipalidad de Obando (Plan Municipal de Desarrollo 2012).

Antes de ser conquistado por los Incas, el territorio donde se ubica Gualmatán estaba habitado por tribus Quillacingas, pertenecientes a la gran familia Chibcha. A mediados del siglo XV, los grupos del Inca Tupac Yupanqui llegaron por el sur hasta las tierras de los Araucanos y en el norte se empeñaron en una guerra contra la confederación de los Caras en el Ecuador y demás tribus que quedaban más al norte, es decir, lo que hoy ocupa el departamento de Nariño. Por tal razón, esta región entró a formar parte del gran imperio Inca y adoptó sus costumbres, lengua, religión y formas de gobierno (Plan Municipal de Desarrollo 2012). 
Donde actualmente se encuentra el municipio de Gualmatán existió el ayllu de Yaesnán, lo que indica que el primitivo nombre y pueblo de este lugar fue Yaesnán; y el ayllu de Champutis, nombre primitivo que se le dio al lugar donde se encuentra lo que hoy se denomina como el corregimiento de Cuatis (Plan Municipal de Desarrollo 2012). En 1547 Gualmatán deja de pertenecer a los Quillacingas, pasó a ser el lugar donde se alojaban los caminantes, el imperio Inca quería apoderarse de ellos pero estos ofrecieron resistencia. En Crónica del Perú. El Señorío de los Incas, Pedro de Cieza de León afirma:

\section{La Villa de Pasto está fundada en el} Valle de Atris, que cae en la tierra de los Quillacingas, gentes desvergonzadas, y ellos y los Pastos son muy sucios y tenidos en poca estimación de sus comarcanos. Saliendo de la villa de Pasto, se va hasta llegar a un cacique o pueblo de los pastos llamado Funes. Y caminando más adelante se allega a otro que está de él poco más de tres leguas, a quien llaman Iles. Y otras tres leguas más adelante se ven los aposentos de Gualmatán. Y prosiguiendo el camino hacia Quito se ve el pueblo de Ipiales, que está de Gualmatán tres leguas. En todos estos pueblos se da poco maíz o casi ninguno, a causa de la tierra muy fría, y de la semilla del maíz muy delicada, más críanse abundancia de papas y quinio, y otras raíces que los naturales siembran (De Cieza de León 2005:106).

Los indígenas que habitaron la región que hoy ocupa Gualmatán fueron de la tribu de los Cuatis, que vivían en la ribera de su río que llevaba el mismo nombre e integraban la familia de los Pastos. Al paso de los conquistadores, estos opusieron resistencia a sus pretensiones y libraron muchas batallas cuando los conquistadores peruanos quisieron someterlos; en conmemoración a este triunfo plantaron una piedra en lo que hoy ocupa el municipio (Plan Municipal de Desarrollo 2012).

El municipio de Gualmatán se encuentra localizado en el centro de la región andina colombiana, en la zona montañosa al sur del departamento de Nariño. Su altura sobre el nivel del mar es de 2.830 metros, y su temperatura media es de $13^{\circ} \mathrm{C}$. Gualmatán presenta una extensión territorial de 36 $\mathrm{km}^{2}$, la mayor parte de su territorio es montañoso, distribuyéndose sus pisos térmicos en frío con aproximadamente $21 \mathrm{~km}^{2}$ y páramo con aproximadamente $15 \mathrm{~km}^{2}$ (DANE 1995).

\section{Tipos de compadrazgos y las maneras de constituirlos}

La presencia del compadrazgo en Gualmatán es trascendental para sus habitantes, siempre tejen su memoria a partir de sus compadres. El recuerdo del pasado se llena de nostalgia bajo los códigos normativos-morales que la institución del compadrazgo contenía:

Anteriormente los compadres eran muy respetados, entre los compadres no se podía "chistear", siempre eran relaciones de mucho respeto y con los ahijados era igual. Muchas veces en el caso de los ahijados no podían hablar dentro de una conversación sino cuando se le permitía (Entrevistado, Gualmatán, Mayo de 2014).

Para la institución del compadrazgo en Gualmatán es importante la permanencia y persistencia de la Iglesia católica. Ella posibilita que aún existan lazos de compadrazgo entre los campesinos y -ahora- los no campesinos. Adicionalmente, las fiestas de los habitantes de Gualmatán, muchas de ellas enmarcadas en las celebraciones de los sacramentos católicos, son un escenario propicio para rememorar los lazos de compadrazgo.

A partir del trabajo etnográfico en Gualmatán fue posible observar lazos de compadrazgo de carácter horizontal y vertical que se sostienen en el tiempo, pero que se han transformado por los procesos modernizantes del cambio agrario. Además, con la relación de compadrazgo y reciprocidad es posible comprender los mecanismos de reciprocidad presentes en Gualmatán, como la minga, el enchacle, el enteje, la payácua y las torrejas.

En Gualmatán existen cuatro acontecimientos en donde se pueden establecer lazos de compadrazgo. Tres de ellos hacen parte de los rituales de la Iglesia católica, por esa razón pueden definirse como compadrazgos sacramentales, estos son: bautismo, confirmación y matrimonio. El otro acontecimiento se conoce como "la cargada de la guagua de pan", de esta forma se configura un compadrazgo no sacramental $^{8}$. 


\section{Compadrazgos sacramentales: notas acerca del bautismo, el matrimonio y la confirmación}

El bautismo es el rito de iniciación en donde una persona entra a hacer parte de la Iglesia católica, a la par que le permite recibir la identidad como católico (por esa razón al infante se le da un nombre). Como lo señala Enrique Rodríguez (2009), para los católicos el bautismo significa la salvación del hombre, por esa razón existen expresiones metafóricas relacionadas con este rito como limpieza, purificación, nuevo nacimiento, entre otras. Además, "para el cristianismo, el rito del bautismo ha significado y significa también un medio a través del cual se rechaza y aleja al mal" (Rodríguez, 2009:97). En este sentido, el bautismo como rito de iniciación, de identidad, de salvación y de rechazo del mal, simboliza el sacramento más significativo de la Iglesia católica.

En Gualmatán, el más importante de los cuatro acontecimientos para establecer lazos de compadrazgo es el bautismo. Generalmente este ritual se lleva a cabo durante los primeros meses o años de vida del nacido. Justamente como lo define Jesús Contreras, "con motivo del bautismo de un recién nacido, sus padres buscan un padrino y una madrina para el mismo. El recién nacido será el ahijado/a para sus padrinos y los padres del bautizado y sus padrinos serán entre sí compadres y comadres" (Contreras 1979:5).

Entre las primeras obligaciones que ostenta el padrino con su ahijado/a está el de obsequiarle el vestido de bautismo y el cirio para ser encendido durante el rito. Posteriormente, el padrino solemnizará sus obligaciones en la ceremonia católica, entre estas se compromete con sus compadres a educar y "criar" a su ahijado/a como padre o madre si estos llegarán a faltar, además, se compromete a prestar toda la colaboración necesaria que su ahijado/a requiera. Por su parte, las obligaciones entre compadres y comadres se refieren a la colaboración recíproca en los trabajos agrícolas (siembra, cosecha), al intercambio de regalos en las fechas especiales (cumpleaños, día de santo, graduaciones), a la participación y colaboración en las fiestas que preparen para ellos o para sus familiares, y en la construcción o ampliación de la vivienda (que se conoce como enteje).

Era decisión de los padres escoger al padrino de sus hijos y en el caso de los sacramentos a quien lo escogían como padrino no se podía negar, anteriormente existían las obligaciones de que debían cumplir de acuerdo a las posibilidades del padrino. [...] Cuando era joven, en el caso de los compadres que tenían grandes terrenos invitaban a los compadres a sembrar y no le pagaban un diario, sino que al momento de la cosecha se le daba una porción de la misma y ese era el pago, y de esta manera se ayudaban los unos a los otros especialmente con la carga económica. Asimismo, más o menos hace unos 40 años para el día del enteje el compadre vestía a la teja con estrellas, cruces, con el sol, etcétera, y la llevaba vestida para que sea la más visible (Entrevistado, Gualmatán, Mayo de 2014).

El compadrazgo de bautismo puede ser resultado de una alianza horizontal o vertical (compadrazgo horizontal o vertical). En Gualmatán, para establecer lazos de compadrazgo a partir del bautismo, los campesinos-jornaleros prefieren elegir a campesinosagricultores/ganaderos como padrinos de sus hijos, esto les permite generar un vínculo de trabajo a partir de la ocupación de la mano de obra en la producción agrícola de sus compadres (como a la mediería). Lo que demuestra que esta relación no se da entre iguales, es que "muy rara vez el compadre-padrino le da a un compadre-padre la posibilidad de apadrinar un hijo suyo" (Gascón 2005:193).

Por otro lado, los campesinos agricultores/ ganaderos prefieren elegir como padrinos de sus hijos a otros campesinos agricultores/ganaderos, o elijen a personas no campesinos. En el primer caso la alianza posibilita un intercambio económico entre iguales, lo que puede ampliar las fronteras agrícolas y elevar la producción. En el segundo caso, tener un compadre que ostente un empleo burocrático de alto nivel (en la alcaldía, en el banco o en el puesto de salud), permite que los lazos clientelares empiecen a funcionar.

Varios campesinos-agricultores/ganaderos en Gualmatán tienen muchos ahijados/as, uno de ellos menciona que tiene cerca de cincuenta ahijados. "El número y la clase de compadres que tiene un individuo puede ser considerado como un indicador muy significativo y suficientemente preciso de su estatus dentro de la comunidad" (Contreras 1979:12). Sin embargo, los compadrazgos horizontales en 
Gualmatán eran muy habituales, eso explica -como se verá más adelante- la persistencia de instituciones de reciprocidad como la minga, el enteje, la payácua y las torrejas.

Como anota Javier Ferrer, entre 1564 y hasta finales del siglo XIX en Iberoamérica la única forma presente de matrimonio era el matrimonio católico. Este se entiende como el intercambio de voluntades entre el hombre y la mujer, del que surge un vínculo moral y "jurídico perpetuo y exclusivo, que no necesita renovarse cada día" (Ferrer, 2011:395). Para que un hombre y una mujer puedan contraer matrimonio, la Iglesia católica obliga a que estas personas hayan recibido los sacramentos previos (bautismo, comunión y confirmación).

Con esto, pese a que en Colombia se reconoce el matrimonio civil desde fines del siglo XIX ${ }^{9}$, en Gualmatán la mayor parte de matrimonios que se efectúan son católicos. Además, los lazos de compadrazgo únicamente se constituyen con el sacramento católico del matrimonio, el matrimonio civil (o de otra religión) no produce los efectos de obligatoriedad moral que el compadrazgo implica.

Para el caso del matrimonio, segundo acontecimiento importante para establecer lazos de compadrazgo en Gualmatán, la relación fundamental se establece entre padrinos y ahijados. Son las personas que contraen matrimonio (ahijados) quienes eligen a sus padrinos. La obligación de los padrinos, en el plano material, es la de colaborar con determinada cantidad de dinero para que los recién casados puedan organizar su vivienda. En el plano espiritual, a los padrinos les compete evitar la separación de la pareja.

\section{[...] a toda costa, la labor de los padrinos es evitar que los ahijados se separen. A uno le toca aconsejarlos y convencerlos de que sigan juntos. [...] A mí me ha tocado varias veces ir donde los ahijados para hablarles, unos han vuelto, pero unas dos parejitas se me han separado (Entrevistado, Gualmatán, Julio de 2014).}

Los lazos de compadrazgo consecuencia del sacramento del matrimonio generalmente obedecen a una alianza vertical (compadrazgo vertical). Esto se debe a que -como se mencionó anteriormenteel padrino tiene una obligación económica con sus ahijados. Por esa razón, las personas que contraen matrimonio prefieren elegir a personas que ostenten recursos económicos, aquí los preferidos son los campesinos agricultores/ganaderos y los no campesinos que ocupan un empleo destacado. No obstante, la otra obligación del padrino es evitar la separación de sus ahijados, por ese motivo la imagen matrimonial de la persona elegida como padrino es importante, eso puede ser útil para dar ejemplo de sobrellevar y sostener el matrimonio hasta la muerte.

El sacramento de la confirmación es el tercer rito de iniciación de los católicos (los otros dos son el bautismo y la comunión). En este sacramento se consolida y ratifica la pertenecía a la Iglesia católica. Anteriormente, la confirmación se presentaba después del bautismo, cuando se es un infante.

La confirmación, más que un acontecimiento para generar nuevos lazos de compadrazgo, suele ratificar y fortalecer los antiguos. Por lo general la confirmación ratifica los lazos de los padrinos de bautismo. Además, en la confirmación el ahijado/a ya abandonó la etapa de la niñez y ha pasado a la adolescencia (por lo general el sacramento de la confirmación se efectúa entre los 14 y 18 años de edad), lo que le recuerda al padrino sus "nuevas" obligaciones, relacionadas con el trabajo o con la educación universitaria de su ahijado/a.

\section{Compadrazgo no sacramental: "la cargada de la guagua de pan"}

"La cargada de la guagua de pan" fue un acontecimiento que generaba lazos de compadrazgo, pero desde hace-aproximadamente- tres décadas se ha perdido. Este compadrazgo se originaba cuando una persona regalaba a otra una figura de un niño/a (guagua) creada con harina de trigo (pan). El acontecimiento únicamente se presentaba en el período de "amasijos", es decir, cuando se encontraba en época de cosecha de trigo, que posteriormente se molía y amasaba produciendo pan.

La intención principal de "la cargada de la guagua de pan" era incluir en la familia a una persona que no se la había podido integrar por medio del compadrazgo generado por el bautismo. Esto quiere decir que parejas que no tenían hijos, o que sus hijos ya habían sido bautizados, entregaban una guagua de pan a la persona con la que querían establecer lazos de compadrazgo. En este caso, las obligaciones únicamente se generaban entre compadres y comadres, y se equiparaban a las del compadrazgo por bautismo. 
El compadrazgo no sacramental de "la cargada de la guagua de pan" es resultado de una alianza horizontal (compadrazgo horizontal). En Gualmatán este compadrazgo se presentaba entre campesinos-jornaleros o campesinos-agricultores/ ganaderos, siempre que ellos hayan tenido relación con la producción de trigo y el posterior "amasijo". Este tipo de compadrazgo también fue útil para la permanencia de las prácticas de reciprocidad.

\section{Compadrazgo y reciprocidad en Gualmatán}

Según Jorge Gascón (2005), cuando se estudia el compadrazgo es indispensable comprenderlo en su relación con los mecanismos de reciprocidad de bienes y de servicios en los que se fundamenta. En este sentido, como se indicó previamente, entre las primeras funciones del compadrazgo horizontal se encuentra la de incrementar la mano de obra doméstica. No obstante, este incremento solo se "necesita en aquellas épocas de ciclo anual o vital en que el volumen de trabajo sobrepasa la capacidad del grupo doméstico, sin tener que mantenerlo durante todo el año o pagar por él un salario o unos gastos excesivamente onerosos para su economía" (Gascón 2005:198). Esto sucede en el periodo de siembra, cosecha (payácua) y en la construcción de una vivienda (enchacle y enteje).

La minga, de herencia Inca, actualmente se interpreta como la reunión de personas para realizar un trabajo que tiene como propósito un beneficio comunitario, "las partes involucradas son claramente de un estatus común" (Ferraro 2004). En Gualmatán, el llamado a la minga se hace para la construcción, adecuación, ampliación o mejoramiento de un bien general, como acueductos, carreteras, parques, polideportivos y escuelas. Sin embargo, bajo la misma lógica de reciprocidad, en Gualmatán se presentaba el enchacle, el enteje, la payácua y las torrejas.

El enchacle consistía en el trabajo tendiente a la elaboración de las paredes de la casa. Anteriormente, las paredes se construían con madera y barro pisado, por esa razón se necesitaba numerosa mano de obra. El día del enchacle acudían familiares, compadres, amigos y vecinos, "al terminar el trabajo, se ofrecía una gran fiesta como agradecimiento, y en ella, el propietario ofrecía todo tipo de comidas y bebidas" (Quiroz 2013:78).

En el enteje se reunía a todos los amigos, vecinos y compadres, "quienes llegaban a prestar mano de obra, en demostración de auténtica solidaridad y amistad" (Quiroz 2013:78). El propósito era colocar las tejas de barro sobre las paredes que recientemente habían sido construidas. Los compadres llevaban una teja decorada para ponerla en un lugar visible de la nueva vivienda (le llamaban la "teja vestida"). Los propietarios, por lo general una pareja de recién casados, se encargaban de suministrar la comida y la bebida (licor). La fiesta de la inauguración de la vivienda se extendía por varias horas e incluso podía durar algunos días.

La payácua es la forma de reciprocidad más recordada en Gualmatán. Se fundamentaba en las necesidades que surgían durante el tiempo de la cosecha. Cuando alguien estaba cosechando, los familiares, amigos, compadres o vecinos, visitaban la cosecha y le llevaban alimentos o bebidas. De esta forma, la entrega de ese obsequio posibilitaría la culminación del trabajo. Finalizada la cosecha, el propietario visitaba a las personas que le llevaron la payácua y les entregaba una porción de los productos cosechados (papas, habas, arracachas, maíz).

Las torrejas fueron una práctica de reciprocidad circunscrita -mucho más- a los lazos de compadrazgo. Cuando una persona cosechaba, en seguida visitaba la casa de sus compadres con la intención de entregar en forma de regalo una porción de sus productos. Siempre la visita a un compadre debía ir acompañada de un obsequio.

Hoy, varias de estas prácticas de reciprocidad han desaparecido. Muy pocas sobreviven, y otras han sido transformadas para adaptarse a las nuevas necesidades. Por esta razón, la institución del compadrazgo, que necesitaba de las prácticas de reciprocidad y de las fiestas para materializar sus lazos, ha entrado en crisis.

\section{Disolución, Transformación y Adaptación del Compadrazgo}

El proyecto modernizante, implementado y generalizado durante el siglo XX en América Latina, modificó lógicas sociales y económicas en las que se sostenía la producción campesina. Como resultado de - pretender- modernizar la producción agrícola en las zonas rurales, se instauraron procesos de cambio agrario que desencadenaron algunas alteraciones en el uso y tenencia de la tierra y en la reconfiguración de la familia campesina, entre muchas otras.

En los Andes de Colombia, específicamente en el municipio de Gualmatán, los procesos de cambio 
agrario alteraron la parte esencial del sostenimiento de la economía campesina: la familia campesina. De esta forma, la institución del compadrazgo, que otrora servían a la producción de la familia campesina extendida, se ha visto sumergida en procesos de disolución, transformación y adaptación.

Concretamente, la institución del compadrazgo en Gualmatán se ha visto amenazada por dos aspectos que los procesos de cambio agrario han generado. El primero es la desaparición de varias prácticas de reciprocidad y, el segundo, el incremento de los procesos migratorios hacia los centros urbanos.

En Gualmatán las prácticas de reciprocidad han sido afectadas por los procesos de cambio agrario. Las nuevas lógicas de maximización de la producción agraria difundieron la inserción del trabajador asalariado en el campo. En consecuencia, prácticas de reciprocidad que implicaban la colaboración en los momentos de siembra y cosecha-como la payácua- han desaparecido.

En igual sentido, las torrejas, que se presentaban con posterioridad a la cosecha, han sido olvidadas. El excedente de la producción agrícola no se destina a la entrega de obsequios a los compadres. Teniendo en cuenta la elevada inversión económica en la producción, los altibajos en los precios del mercado agrícola y los nuevos gastos de los campesinos (como el pago de servicios públicos domiciliarios, telefonía, televisión, matrículas educativas, entre otras), la totalidad de la producción agrícola debe venderse en el mercado.

Igualmente, con el arribo del proyecto modernizante se ha dado paso a la inclusión de diseños arquitectónicos para la construcción de viviendas en Gualmatán. La llegada del ladrillo, el cemento, la teja de eternit, el techo acrílico, han dispuesto la desaparición de los muros construidos a partir de la tapia pisada y la teja de barro, lo que a su vez ha extinguido el enchacle.

Además, el enteje se ha modificado por las lógicas del trabajo asalariado y por la desaparición de las tejas de barro. No obstante, aún subsiste -en menor medida- como práctica de reciprocidad. Actualmente el enteje se presenta en la construcción de la vivienda de concreto, en ese momento acuden las personas cercanas al propietario de la vivienda a prestar su mano de obra, en contraprestación el propietario dispone de alimentos y bebidas. La magnitud del acontecimiento no es la misma que la de hace algunos años, pero se ha adaptado al nuevo contexto de Gualmatán.
Otro tipo de compadrazgo que ha desaparecido completamente en Gualmatán es el compadrazgo no sacramental de "la cargada de la guagua de pan". Su desaparición obedece a que hoy se presentan muy pocos -o casi ningún- "amasijos". Actualmente, como resultado de los procesos de cambio agrario, ya no se cultiva trigo en el municipio. En síntesis, varias prácticas de reciprocidad en Gualmatán han desaparecido. Otras, como el enteje, se han adaptado a los contextos actuales. Esto afectó a la institución del compadrazgo, en tanto ha dejado de percibirse como una posibilidad de incrementar la fuerza de trabajo.

El segundo aspecto fundamental que ha afectado a la familia campesina en Gualmatán son los procesos migratorios. Por distintas causas -como la falta de empleo, estudio o razones familiaresmuchas personas han abandonado el pueblo y se han asentado en otros municipios o ciudades cercanas.

Cuando la migración se produce por falta de empleo, la unidad de producción de la familia campesina se reduce, pero es muy posible que si el miembro de la familia consigue empleo los ingresos se incrementen por cuanto seguirá colaborando económicamente con los gastos domésticos. No obstante, en muchos casos de migración permanente la persona migrante organiza su propia familia nuclear, con lo que se desprende de sus obligaciones económicas con la familia de Gualmatán.

Por otra parte, si la migración se produce porque un miembro de la familia busca estudiar en la ciudad, la familia campesina se ve afectada doblemente: se reduce la unidad de producción y, además, se necesita conseguir más recursos económicos para ayudar a su pariente. Para soportar esta carga económica, la familia campesina acude a los familiares que viven en la ciudad.

Como ya se mencionó, los lazos de compadrazgo son el resultado de una alianza horizontal o vertical, funcionan como una estrategia para conseguir determinados objetivos. De esta forma, las familias que tienen algún pariente estudiando en la ciudad y que no tienen parientes cercanos para solicitarles su ayuda, acuden a los lazos rituales.

Anteriormente en Gualmatán, para establecer lazos de compadrazgo a partir del bautismo, la confirmación o el matrimonio, los campesinosjornaleros preferían elegir a campesinos-agricultores/ ganaderos como compadres y padrinos, esto les permitía generar un vínculo de trabajo a partir de 
la ocupación de la mano de obra en la producción agrícola de sus compadres y recibir ayuda económica -para el caso del compadrazgo por matrimonio-. Este tipo de compadrazgo vertical se ha modificado y adaptado a los contextos actuales.

Debido a la gran afluencia migratoria, los campesinos-jornaleros o los campesinos-agricultores/ ganaderos prefieren elegir a personas asentadas en la ciudad como compadres y padrinos, esto les permite solicitar favores en la ciudad para sus hijos (ahijados) o para ellos (compadres).

El trabajo etnográfico permitió reconstruir el grupo de parentesco de una familia extendida que tiene su origen en Gualmatán (ver Figura 1). De las dos hijas procreadas en segunda generación, una de ellas permanece definitivamente en Gualmatán, la otra emigró con sus hijos/as en la década de 1980 a la ciudad de Pasto. La descendencia de la mujer que permanece en Gualmatán también opta por permanecer en el pueblo, uno de sus hijos es un campesino-agricultor y el otro es un campesinojornalero. Sin embargo, dos miembros de la cuarta generación, hijos del campesino-jornalero, migraron a la ciudad de Pasto para estudiar.
Por su parte, los hijos/as de la mujer que emigró a la ciudad de Pasto trabajan como empleados en algunas entidades reconocidas, todos tienen constituidas familias nucleares. De esta manera, pesé a que las relaciones de compadrazgo se presentan entre parientes, los lazos que se originan son de carácter vertical. En este caso, los lazos de compadrazgo sacramental son más estrechos que los lazos de filiación y afinidad.

Este grupo de parentesco se repite en muchos casos en Gualmatán, donde la institución del compadrazgo sobrevive pero se ha adaptado a los nuevos contextos de migración campo-ciudad.

\section{Conclusiones}

Si bien el análisis "microsocial" despliega algunas desventajas relacionadas con su singularidad, en tanto que torna arbitrario todo intento de generalización, posee una ventaja mayor: posibilita entender las "prácticas concretas de los sujetos sociales (su racionalidad) que 'realizan' cotidianamente la reproducción social, como opciones posibles -estrategias- dentro del marco de las

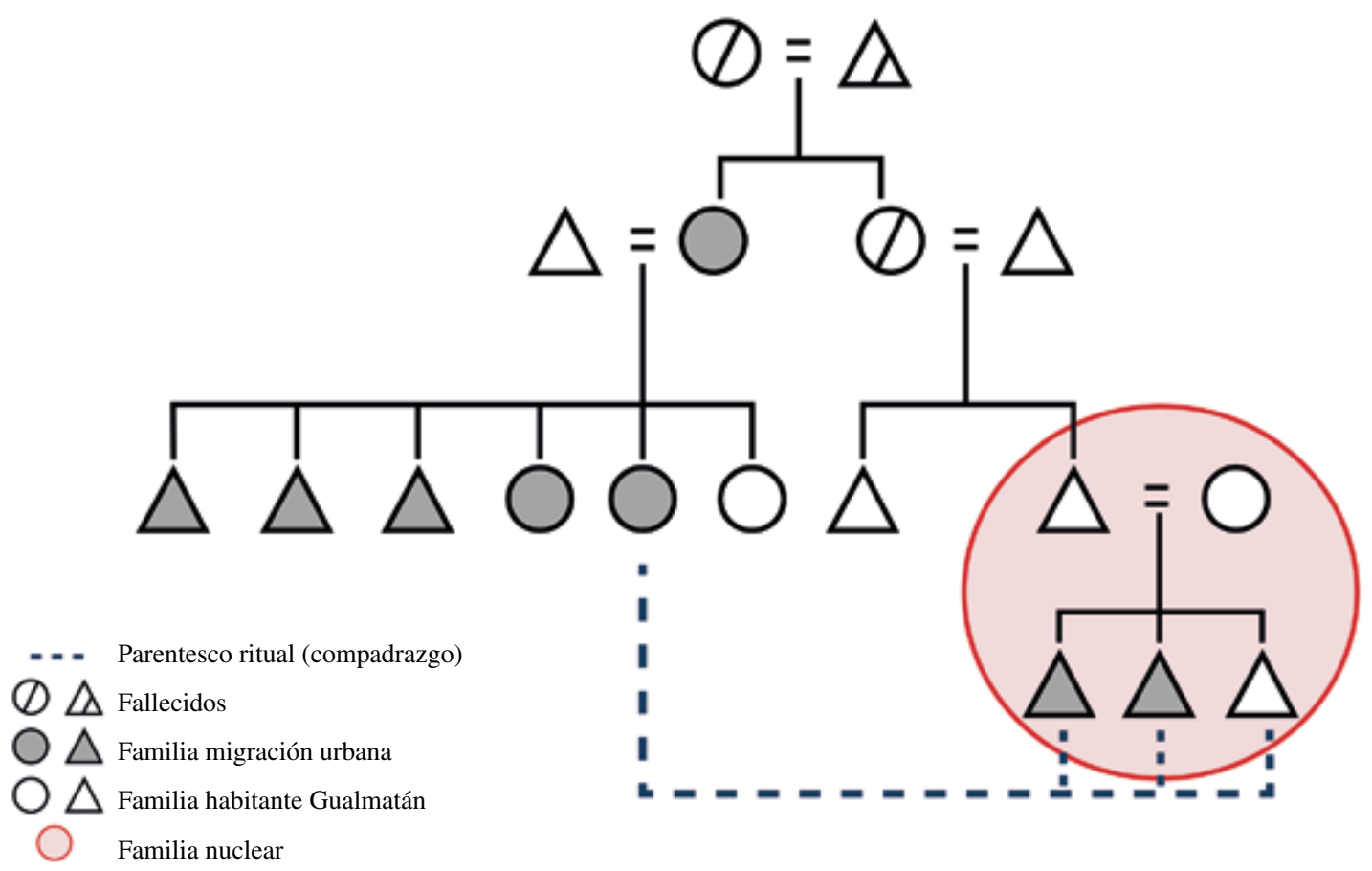

Figura 1. Grupo de parentesco de una familia extendida en Gualmatán.

Kingroup of an extended family in Gualmatán.

Fuente: Esta investigación. 
determinaciones sociales de orden estructural" (Guerrero 1991:109).

En este sentido, el trabajo de campo realizado en Gualmatán permite, en primer lugar, comprender la institución del compadrazgo como una estrategia de reproducción que se sustenta en las prácticas de reciprocidad andina. En segundo lugar, permitió evidenciar la incidencia del cambio agrario en la disolución, transformación y adaptación de la institución del compadrazgo en Gualmatán; lo que a su vez trastocó las lógicas tradicionales en las que se soportaba la producción agrícola de la familia campesina.
El siglo XX trajo para los campesinos de Gualmatán una transformación profunda en la cotidianidad y algunas promesas sin cumplir.

\section{Agradecimientos}

Quiero expresar mis agradecimientos a la Universidad Cooperativa de Colombia (UCCPasto) y a la Facultad Latinoamericana de Ciencias Sociales (FLACSO-Ecuador) por la financiación del trabajo de campo. Asimismo, agradezco a los entrevistados y fuentes sobre las que se basa este artículo.

\section{Referencias Citadas}

Alberti, G. \& Mayer, E.

1974 Reciprocidad e intercambio en los Andes Peruanos. Lima: Institutos de Estudios Peruanos.

Chayanov, A.

1974 La organización de la unidad económica campesina. Buenos Aires: Ediciones Nueva Visión.

Contreras, $\mathrm{J}$.

1979 "El compadrazgo y los cambios de estructura de poder local en Chinchero-Perú". Boletín Americanista 29: 5-29.

Cieza de León, P.

2005 Crónica del Perú. El Señorío de los Incas. Venezuela: Biblioteca Ayacucho.

Eggan, F.

1975 "Parentesco", en David Sills (coord.), Enciclopedia Internacional de las Ciencias Sociales, vol. 7: 583-586. Madrid: Editorial Aguilar.

Ferraro, E.

2004 Reciprocidad, don y deuda. Relaciones y formas de intercambio en los Andes ecuatorianos: la comunidad de Pesillo. Quito: Abya-Yala.

Ferrer, J.

2011 "Del matrimonio canónico como modelo al matrimonio civil deconstruido: la evolución de la legislación española". Revista Ius et Praxis 17 (2): 391-418.

Foster, G.

1953 "Cofradía and Compadrazgo in Spain and Spanish America". Southwestern Journal of Anthropology 9: 1-28.

Gascón, J.

2005 "Compadrazgo y cambio en el Altiplano peruano". Revista Española de Antropología Americana 35: 191-206.

Guerrero, A.

1991 De la economía a las mentalidades. Cambio social y conflicto agrario en el Ecuador. Quito: Editorial El Conejo.

Golte, J. \& De la Cadena, M.

1986 La codeterminación de la organización social andina. Documento de trabajo No. 13. Lima: IEP Instituto de Estudios Peruanos.

Harris, M.

1990 Antropología Cultural. Madrid: Alianza Editorial.
Jáuregui, J.

1982 "Las Relaciones de Parentesco". Revista Nueva Antropología 18 (5): 179-198.

Lévis-Strauss, C.

1995 Antropología Estructural. Barcelona: Paidós.

Lévis-Strauss, C.

1998 La estructural elemental del parentesco. Barcelona: Paidós.

Malinowski, B.

1986 Los argonautas del Pacífico occidental. Barcelona: Planeta-Agostini.

Mauss, $\mathrm{M}$.

2009 Ensayo sobre el don. Forma y función del intercambio en las sociedades arcaicas. Madrid: Katz Editores.

Mintz, S. \& Wolf, E.

1994 "Análisis del parentesco ritual (compadrazgo)", en Marco Rueda y Segundo Moreno (coords.), Cosmos, Hombre y Sacralidad: 371-411. Quito: PUCE y Abya Yala.

Mitchell, W.

1994 "Algunos son más iguales que otros. Oferta de mano de obra, reciprocidad y redistribución en los Andes". Anthropologica 11: 174-207.

Narotzky, S.

2010 "Reciprocidad y capital social: modelos teóricos, políticas de desarrollo, economías alternativas. Una perspectiva antropológica”, en Víctor Bretón (ed.), Saturno devora a sus hijos. Miradas críticas sobre el desarrollo y sus promesas: 127-174. Barcelona: Icaria Editorial.

Nutini, H. \& Bell, B.

1989 Parentesco Ritual. México D.F.: Fondo de Cultura Económica.

Pitt-Rivers, J.

1975 “Seudoparentesco", en David Sills (coord.), Enciclopedia Internacional de las Ciencias Sociales, vol. 7: 596-601. Madrid: Editorial Aguilar.

Polanyi, K.

1989 La gran transformación. Crítica del liberalismo económico. Madrid: Ediciones de La Piqueta.

Quiroz, J.

2013 Gualmatán: tierra de ensueño y fantasía. Ipiales: Cedigraf Editores. 
Radcliffe-Brown, Alfred y Cyril Daryll Forde 1982 Sistemas africanos de parentesco y matrimonio. Barcelona: Anagrama.

Rodríguez, E.

2009 "Gesto y ritual. Lecturas sobre el bautismo entre los mayas contemporáneos". Península 4 (1): 93-116.

Salazar, H. F.

2010 Cultura de las comunidades andinas. Un acercamiento a su resignificación de los poderosos forasteros: el caso de Julo Chico. Tesis de Maestría en Ciencias Sociales, Facultad Latinoamericana de Ciencias Sociales, México.

Scott, J.

1987 "Peasant Moral Economy as a Subsistence Ethic", en Teodor Shanin (comp.), Peasants and Peasant Societies: 304-310. New York: Basil Blackwell.
Thompson, E. P.

1991 Costumbres en común. Barcelona: Crítica Grijalbo Mondadori.

Thurnwald, R.

1932 Economics in primitive communities. London, Oxford University Press.

Wolf, E.

1978 Los campesinos. Barcelona: Editorial Labor S.A.

\section{Documentos de Gobierno}

Alcaldía Municipal de Gualmatán. Plan Municipal de Desarrollo, Gualmatán 2012-2015.

Departamento Administrativo Nacional de Estadística DANE. Anuario Estadístico de Nariño 1993-1994.

Notas

1 Como afirma Fred Eggan, el empleo del término "sistema" implica que existe una compleja relación de interdependencia entre las partes componentes: las categorías sociales y los correspondientes derechos y obligaciones (1975). $\mathrm{Al}$ respecto también véase a Lévis-Strauss, Antropología Estructural, donde ha puesto de relieve la relación entre la lingüística estructural y el estudio del parentesco: “[...] como los fonemas, los términos de parentesco son elementos de significación; como ellos, adquieren esta significación solo a condición de integrarse en sistemas; los "sistemas de parentesco", como los "sistemas fonológicos", son elaborados por el espíritu en el plano del pensamiento inconsciente; la recurrencia, en fin, en regiones del mundo alejadas unas de otras y en sociedades profundamente diferentes, de formas de parentesco, reglas de matrimonio, actitudes semejantes prescritas entre ciertos tipos de parientes, etcétera, permite creer que, tanto en uno como en otro caso, los fenómenos observables resultan del juego de leyes generales pero ocultos" (1995: 78).

2 Como asegura Jesús Jáuregui, los hechos biológicos subyacen al parentesco, pero de ninguna manera lo constituyen: no son pertinentes en cuanto tales, sino solo a partir de su reinterpretación cultural-simbólica (Jáuregui 1982).

3 Cuando hablo de "parentescos tradicionales" me refiero a la clasificación de filiación y afinidad propuesta por los antropólogos Marvin Harris, Claude Lévi-Strauss y Radcliffe-Brown.

$4 \quad$ El trabajo de campo realizado en Gualmatán permitió comprender la coexistencia de tres grupos poblacionales determinados según su ocupación laboral. Los campesinos-agricultores/ganaderos son los medianos y grandes propietarios de la tierra, que se dedican a la producción agrícola o ganadera propia. Los campesinos-jornaleros son los propietarios de pequeñas porciones de tierra o, en algunos casos, campesinos sin tierra que deben vender su fuerza de trabajo a cambio de un salario (jornal) para su subsistencia. Por último, el grupo poblacional denominado los no campesinos son los habitantes de Gualmatán que no tienen una relación directa con el trabajo agrícola o ganadero -indistintamente si son o no dueños de la tierra-, y que dedican su tiempo laboral en el comercio o en algún empleo público o privado.

5 En La gran transformación Karl Polanyi acude a los trabajos etnográficos de Malinowski y Thurnwald para comprender y analizar dos principios de comportamiento que a primera vista no suelen ser asociados con la economía: la reciprocidad y la redistribución. Ver: Malinowski, B. 1986. Los argonautas del Pacífico occidental. Barcelona, Planeta-Agostini; y Thurnwald, R. 1932. Economics in primitive communities. London, Oxford University Press.

6 El concepto de ayllu puede tener diferente significado, por un lado se puede entender como la familia nuclear base de la comunidad andina, pero también la reunión de muchas familias que comparten vínculos espirituales, territoriales, económicos y con antepasados comunes.

7 Existen dos tipos de intercambio, simétrico y asimétrico. El primero se realiza entre dos iguales: lo recibido debe corresponder a lo dado. El segundo, los bienes entregados a cambio del trabajo tienen valor variable o no ser equivalentes al esfuerzo gastado. Esta puede crear variaciones y resulta en una redistribución, influyendo en la organización social de un ayllu (Alberti y Mayer 1974: 14).

8 La clasificación entre compadrazgo sacramental y compadrazgo no sacramental es acuñada por Hugo Nutini y Betty Bell (1989) en el libro acerca del estudio del compadrazgo en el sector rural de Tlaxcala, México. Ver: Nutini, H y Bell, B. 1989. Parentesco Ritual. México D.F., Fondo de Cultura Económica. pp. 66-68.

9 En el gobierno liberal de José María Obando se sancionó en Colombia la primera Ley de Matrimonio civil (Ley del 20 de junio de 1853). No obstante, esta ley se encontraba determinada por las reglas del matrimonio católico. 
